\title{
The role of response effort in extinction: Much ado about nothing
}

\section{THOMAS STACHNIK ${ }^{1}$ \\ ILLINOIS WESLEYAN UNIVERSITY}

In order to determine the inportance of response effort in operant extinction, albino rats $(N=21)$ were trained on differentially weighted bars in an operant chamber and then extinguished to a 5 min no-response criterion. By using a recessed bar and by giving substantially greater training than in previous studies, the inverse rclationship between response effort and resistance to extinction noted in earlier studies failed to appear.

Some introductory textbooks (Kendler, 1963; Lewis, 1963) suggest that the effort requirement is an important consideration in operant extinction. Studies are cited (Mowrer \& Jones, 1943; Capehart, Viney, \& Hulicka, 1958) which indicate that resistance to extinction is an inverse linear function of the effort required to depress a bar in an operant chamber. However, the fact that other studies have failed to confirm that finding (Maatsch, Adelman, \& Denny, 1954; Aiken, 1957) and the existence of certain unresolved problems characteristic of effort variable research make a statement of such a relation something less than definitive.

One problem has been that conclusions have been drawn on the basis of small samples of behavior. For example, in the Capehart et al (1958) study, the animals' total training consisted of only 90 bar presses, 30 at each of three bar-loadings $(5,40$ and $70 \mathrm{~g})$. In addition to a minimal amount of overall training, it can be argued that in this particular study the animals were especially short-changed in terms of high-effort training. Although the investigators equated the number of responses made at each bar-loading $(30)$, it might be said that they failed to control for high and. low effort response strength because of the assumption that rats trained to press light bars will press heavier bars with equal facility. It seems legitimate to consider the reinforcement of a bar press at a given loading to reinforce that response for all bars of equal or lesser weight, but not for bars of greater weight. In this sense, then, $70 \mathrm{~g}$ and $40 \mathrm{~g}$ responses must be counted as training for a $15 \mathrm{~g}$ response, but $15 \mathrm{~g}$ and $40 \mathrm{~g}$ responses are not training for a $70 \mathrm{~g}$ response. This would mean that in the Capehart et al study each animal made 90 reinforced light-bar responses but only 30 reinforced heavy-bar responses; therefore, the presumed relationship between response effort and resistance to extinction is confounded with differences in training. In a similar vein, discrepancies between heavy-bar and light-bar training are readily apparent in the Mowrer \& Jones (1943) study previously cited. One possible solution to this problem is to greatly increase training clearly beyond asymptotic level so that it simply is not reason- able to attribute extinction differences to differential amounts of training.

A second and rather major problem common to all effort variable research is essentially a methodological one which concerns the differential sensitivity of the response bar during extinction (Stachnik, 1963). Since the number of responses made in an operant chamber are typically recorded electrically, the criterion for a response is simply a given excursion of the bar. This allows for precise measurement of the number of the responses made, but when the bar is differentially weighted, certain disadvantages are also apparent. During extinction on a light-bar (5-15 g), many tangential or incidental moves made by the animal around the bar are recorded as responses because of the light-bar sensitivity. This is not true when the animal is extinguished on a heavy-bar (80-150 g) which requires a well-executed response to move the bar the prescribed distance. Since "accidental" responses on a light-bar are not an infrequent occurrence during extinction, it is quite possible that this is an important factor in light-bar animals showing a greater resistance to extinction. One possible solution to this problem is to utilize a small response bar which is recessed into the wall of the chamber so that "accidental" responses are virtually eliminated.

\section{Method}

Twenty-one male rats of the Holtzman strain were reduced to $80 \%$ of their free-feeding weight and then shaped to bar press for food in an operant chamber approximately 12 in. $x 12$ in. $x 12$ in. The chamber was housed inside a large sound-attenuated chest; a speaker mounted on the top of the inner chamber provided masking noise. An exhaust fan provided additional masking noise as well as ventilation. The response bar was T-shaped, the cross-member of which measured 1 in., and was recessed into an opening in the chamber wall approximately $1-1 / 2$ in. square. For some animals $(\mathrm{N}=15)$, the bar was retained by an electromagnet whose field could be varied electrically. A limit switch insured that the bar was returned to its original position before subsequent depressions would be counted as responses. For the remaining animals $(\mathrm{N}=6)$, the bar was counterweighted so that the animal had to exert the specified amount of force through the entire excursion of the bar. The effort requirement could be set as low as $15 \mathrm{~g}$, as high as $150 \mathrm{~g}$, or at any value in between.

After shaping, the first session consisted of 100 reinforced bar presses on a continuous reinforcement schedule. The effort requirement at the beginning of the 
session was set at $15 \mathrm{~g}$ and then slowly increased until by the end of the session all Ss were able to make a $150 \mathrm{~g}$ response. The next 15 days of training consisted of five sessions at each of three bar loadings, $15 \mathrm{~g}, 80 \mathrm{~g}$, and $150 \mathrm{~g}$, ordered in a counterbalanced design. A fixed-ratio three (FR 3) reinforcement schedule was in effect during these 15 sessions, with $s$ single session defined as 100 reinforced responses, therefore 300 total responses. Over the 15 days, a total of 4500 responses was made, 1500 at each of the three bar loadings employed. Following this training, each $S$ was extinguished to a $5 \mathrm{~min}$ no-response criterion at either $15 \mathrm{~g}, 80 \mathrm{~g}$, or $150 \mathrm{~g}$. These three extinction groups were equated in terms of the mean response rate during the last three days of training. On the day following extinction, each $S$ was again placed in the chamber and a spontaneous recovery measure obtained to the same 5 min no-response criterion.

\section{Results and Discussion}

The mean number of responses made during extinction and spontaneous recovery at each of the three barloadings is presented in Fig. 1. The most striking feature of these data is the total absence of any lawfulness. The functions tend to be non-linear, and where there is linearity it is not in the direction that previous studies would have predicted.

Figure 2 shows that although overall response rates were slightly lower on the counterweighted bar, the three bar-loadings employed had virtually no effect on response rate during training.

The conclusion which seems most warranted is that within certain parameters the importance of the effort variable in extinction has been greatly over-emphasized. It should be added, however, that this conclusion is made only for the values of the effort variable which have been employed in this and selected previous studies. It seems obvious that the effort requirement can be in-

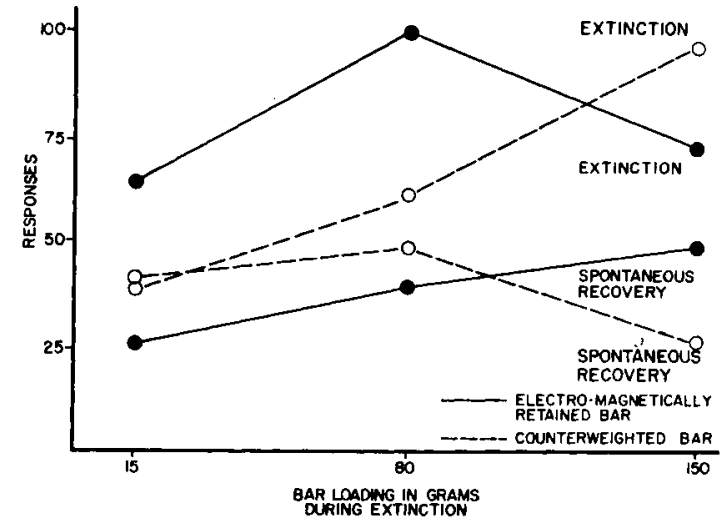

Fig. 1. Mean number of responses made during extinction and spontaneous recovery to a $5 \mathrm{~min}$ no-response criterion.

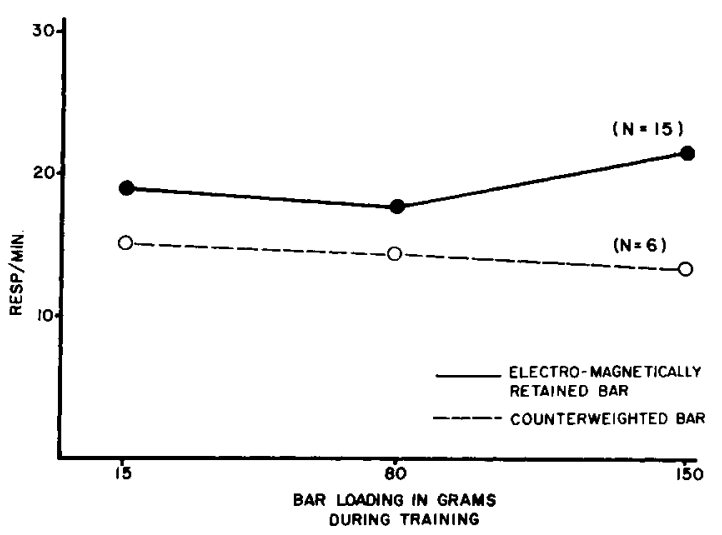

Fig. 2. Response rate per min averaged over all 15 days of training.

creased to the point where it would affect response rate, resistance to extinction and would, in fact, be aversive. For example, Miller (1967) has shown that humans will emit a vocal response in order to escape for $60 \mathrm{sec}$ from one lever that required a 20-1b pull to another one that required a $1-\mathrm{lb}$ pull.

Chung (1965) found that with pigeons trained to make a key-peck response, response rate was unaffected by increases in the effort requirement up to a certain point (approximately $200 \mathrm{~g}$ ); beyond that point, increments caused a proportional decrement in rate. This suggests that in the present study the highest effort requirement of $150 \mathrm{~g}$ is below the critical force value for rats, and that previous studies which employed only a 70 or $80 \mathrm{~g}$ requirement failed to even approach the critical level.

\section{References}

AIKEN, E. G. The effort variable in the acquisition, extinction, and spontaneous recovery of an instrumental response. J. exp. Psychol., $1957,53,47-51$.

CAPEHART, J., VINEY, W., \& HULICKA, I. The effect of effort upon extinction. J. comp. physiol. Psychol., 1958, 51, 505-507.

CHUNG, SHIN-HO. Effects of effort on response rate. J. exp. Anal. Behav., 1965, 8, 1-7.

KENDLER, H. H. Basic psychology. New York: Appleton-CenturyCrofts, 1963.

LEWIS, D. J. Scientific principles of psychology. New Jersey: Prentice-Hall, 1963.

MAATSCH, J. L., ADELMAN, M., \& DENNY, M. R. Effort and resistance to extinction of the bar pressing response. J. comp. physiol. Fsychol, 1954, 47, 47-50.

MILLER, L. K. Escape from force. Paper presented at the proceedings of the American Psychological Association, Washington, D. C., September, 1967.

MOWRER, O. H., \& JONES, H. M. Extinction and behavior variability as functions of effortfulness of task. J. exp. Psychol. 1953, 33, 369-386.

STACHNIK, T. J. A habit-strength analysis of the relationship between response effort and resistance to extinction. Unpublished doctoral dissertation, Michigan State University, 1963.

Note

1. Now in the Division of Research, Planning and Development, Department of Mental Health, Lansing, Michigan. 